\title{
O ensino explícito da compreensão da leitura. Análise do impacto de um programa de intervenção*
}

FERNANDA LEOPOLDINA VIANA Universidade do Minho, Braga, Portugal

IRENE CADIME Universidade do Minho, Braga, Portugal

SANDRA SANTOS Universidade do Minho, Braga, Portugal

SARA BRANDÃO Universidade do Minho, Braga, Portugal

IOLANDA RIBEIRO Universidade do Minho, Braga, Portugal

\section{RESUMO}

Neste artigo apresenta-se o programa Aprender a compreender torna mais fácil o saber, destinado a alunos do $3^{\circ}$ e $4^{\circ}$ anos de escolaridade, que tem como objetivo principal o desenvolvimento das competências de compreensão da leitura, de estratégias de leitura e de metacompreensão. O programa foi implementado com 1.142 alunos do $4^{\circ}$ ano de escolaridade. $\mathrm{Na}$ avaliação dos resultados, recorreu-se a um design de grupo único com pré e pós-teste. Os resultados indicaram a presença de diferenças estatisticamente significativas entre os dois momentos de avaliação, e os resultados obtidos por esses alunos no exame de língua portuguesa de 2012 mostraram que: a percentagem de alunos que obtêm a classificação $\mathrm{A} e \mathrm{~B}$ é superior à média nacional; a percentagem dos que obtêm $\mathrm{D}$ e $\mathrm{E}$ é inferior à média nacional. Apontam-se como linhas de investigação futura a replicação do estudo com a inclusão de um grupo de controlo e a avaliação da perceção dos professores sobre o programa e a sua eficácia.

\section{PALAVRAS-CHAVES}

leitura; compreensão da leitura; programa de intervenção; avaliação.

* O programa Aprender a compreender torna mais fácil o saber foi financiado por Didaxis - Cooperativa de Ensino, CRL; Câmara Municipal de Vila Nova de Famalicão; Centro de Investigação em Psicologia da Universidade do Minho (CIPSI); Centro de Investigação em Estudos da Criança da Universidade do Minho (CIEC). 


\title{
THE EXPLICIT TEACHING AF READING COMPREHENSION. IMPACT ANALYSIS OF AN INTERVENTION PROGRAM
}

\begin{abstract}
In this paper, the intervention program Aprender a compreender torna mais fácil o saber for $3^{\text {rd }}$ and $4^{\text {th }}$ primary school grades is presented. Its main goal is to develop students' reading comprehension, reading strategies and metacomprehension competences. The program was administered to a sample of 1,142 students of the $4^{\text {th }}$ grade. The evaluation of results was designed as a single group with both pre- and post-tests. The results showed statistically significant differences between both moment of evaluation, and the results obtained by these students in the Portuguese Language Exam in 2012 showed that: the percentage of students that obtained $\mathrm{A}$ and $\mathrm{B}$ scores was higher than the national average; the percentage of the ones who obtained D and E scores was lower than the percentages obtained nationally. Future studies should be designed with the inclusion of a control group and should evaluate teachers' perceptions about the program and its efficacy.
\end{abstract}

KEYWORDS

reading; reading comprehension; metacomprehension; intervention program; evaluation..

\section{LA ENSEÑANZA EXPLÍCITA DE LA COMPRENSIÓN LECTORA. ANÁLISIS DEL IMPACTO DE UN PROGRAMA DE INTERVENCIÓN}

\section{RESUMEN}

Este artículo presenta el programa Aprender a compreender torna mais fácil o saber, para alumnos de $3^{\circ}$ y $4^{\circ}$ de la escolaridad primaria, y tiene como su objetivo principal el desarrollo de las habilidades de comprensión lectora, de estrategias de lectura y de metacomprensión. El programa se implementó con 1.142 estudiantes de $4^{\circ}$ grado. Para evaluar los resultados se utilizó un diseño de grupo único con pre y post-test. Los resultados indicaron diferencias estadísticamente significativas entre los dos momentos de evaluación y los resultados obtenidos por estos estudiantes en el de examen de lengua portuguesa en 2012 revelaron que: el porcentaje de estudiantes que obtuvieron la clasificación $\mathrm{A}$ y $\mathrm{B}$ es más alto que el promedio nacional; el porcentaje de aquellos que obtuvieron $\mathrm{D}$ y E es menor que el promedio nacional. Se señalan cómo directrices para futuras investigaciones un estudio con la inclusión de un grupo control y la evaluación de la percepción de los maestros sobre el programa y su eficacia. 
INTRODUÇÃO

Eu acho que não gostava de ler porque não compreendia o que lia... E não percebia que não compreendia...

Joel, aluno do $4^{\circ}$ ano

Neste artigo apresenta-se um programa de ensino explícito da compreensão da leitura - Aprender a compreender torna mais fácil o saber (Viana et al., 2010a) destinado ao $3^{\circ}$ e $4^{\circ}$ anos do $1^{\circ}$ ciclo do ensino básico ( $3^{\mathrm{a}}$ e $4^{\mathrm{a}}$ séries), bem como os resultados do seu impacto com alunos do $4^{\circ}$ ano de escolaridade de um município do norte de Portugal. Esse programa, cujos objetivos gerais são o ensino explícito da compreensão da leitura, o desenvolvimento das competências de compreensão da leitura e o desenvolvimento de estratégias de metacompreensão, é o resultado de três anos de investigação-ação associada ao Projeto Litteratus. O programa foi elaborado para responder à necessidade de elevar os níveis de compreensão dos alunos das séries apresentadas, tendo um cariz marcadamente desenvolvimental que assenta no conceito de zona de desenvolvimento próximo (ZDP) (Vygotsky, 2007). Não se destina, por isso, especificamente a alunos com dificuldades de aprendizagem, mas a todos os alunos. A sua aplicação pode ser individual ou em grupo.

Ler é, por definição, extrair sentido do que é lido, pelo que não se pode falar em leitura se não houver compreensão. A aprendizagem da leitura exige o domínio de um código, mas esse domínio, traduzido na descodificação rápida e automática das palavras, não é suficiente para que o leitor compreenda o que lê. Todavia, a ideia de que, uma vez dominado o código, a compreensão do que é lido acontece está ainda enraizada nas práticas de muitos professores alfabetizadores. Assim, quando se pergunta se é possível ensinar a compreender, as respostas remetem para uma conceção de compreensão como algo que "acontece dentro da cabeça dos alunos" ou que resulta de fatores como a inteligência. A investigação tem mostrado que não só é possível ensinar os alunos a compreender o que leem, mas que é desejável (e urgente) fazê-lo. Para tal, é necessário: 1) que se conheçam os fatores que interferem na compreensão da leitura e; 2) que se usem as estratégias adequadas para guiar os alunos no processo de compreensão. Nos dois primeiros pontos seguintes sintetizar-se-á o estado da arte relativo a esses dois aspetos, explicitando como os resultados da investigação foram operacionalizados no programa. O terceiro ponto será dedicado à avaliação do impacto desse programa.

\section{FATORES QUE INTERFEREM NA COMPREENSÃO DA LEITURA}

É atualmente consensual que a leitura eficiente é o produto de, pelo menos, três tipos de fatores:

1. derivados do texto;

2. derivados do contexto e;

3. derivados do leitor. 
De uma forma necessariamente breve, apresentaremos, de seguida, as principais variáveis incluídas nesses fatores, já que elas enformam o racional teórico do programa Aprender a compreender torna mais fácil o saber e ditam algumas das opções tomadas.

\section{FATORES DERIVADOS DO TEXTO}

Quer os resultados do Programa Internacional de Avaliação de Aluno (PISA) (2001, 2007, 2010), quer a investigação na área da leitura (Curto, Morillo e Teixidó, 2000; Giasson, 2005; Irwin, 1986; Sánchez Miguel, 2002), mostram que o tipo de texto influencia a compreensão da leitura. Dentro dos fatores derivados do texto incluem-se variáveis como o conteúdo, a estrutura, a sintaxe e o vocabulário.

Para que um texto seja compreendido, é necessário que o seu conteúdo seja adequadamente processado e integrado nos conhecimentos possuídos pelo leitor. Assim sendo, é por vezes necessário que antes da leitura se proceda a uma ativação dos conhecimentos considerados indispensáveis para a compreensão do texto a ser lido. Também a própria organização do texto e a sua estrutura interferem na compreensão.

No ensino explícito da compreensão, é necessário prestar atenção ao vocabulário usado nos textos, antecipando que estes podem não ser conhecidos e que se constituem como chave para a compreensão. Essa antecipação não é concorrente da inferência de significados por meio de pistas contextuais (ou linguísticas) ou da pesquisa em dicionários, bem pelo contrário, pois é o recurso a uma multiplicidade de estratégias que promovem o conhecimento ativo da língua. Clarificando, apesar de o vocabulário poder ser um obstáculo à extração de sentido do que é lido, não se sugere que os textos a usar sejam expurgados de palavras consideradas difíceis ou de expressões complexas. Nos manuais escolares para as séries iniciais, é frequente verem-se adaptações de textos que substituem vocábulos ou eliminam expressões, afetando a sua estrutura organizativa e coesão e limitando suas potencialidades para promover a compreensão da leitura.

A seleção dos textos para o ensino da compreensão da leitura deve ainda atender a variáveis como legibilidade (tipo e corpo de letra, entrelinhamento, parágrafos, interrupções de linha...), indicadores tipográficos ${ }^{1}$ (como títulos, subtítulos, sublinhados, negritos, itálicos...), ou as ajudas (como assinalamentos, ${ }^{2}$ comentários, notas de rodapé, ilustrações, sumários, quadros, tabelas, perguntas auxiliares ou organizadores prévios). Essas variáveis, facilmente subalternizadas perante critérios editoriais ou de design gráfico, têm impacto no processo de

1 Há autores que incluem os indicadores tipográficos na categoria assinalamentos tipográficos.

2 Assinalamentos "consistem em informação textual que não acrescenta conteúdos novos, dando apenas ênfase a certos aspectos do conteúdo semântico e da estrutura textual. Essa informação ajuda o leitor a identificar os pontos principais do texto, clarificando as relações hierárquicas e as relações semânticas do texto" (Lencastre, 2003, p. 147). Por exemplo, a presença de conectivas causais (do tipo "porque") melhora a compreensão do texto (Millis e Just, 1994 apud Lencastre, 2003, p. 149). 
compreensão, ajudando (ou não) o leitor a focar a atenção na informação relevante (Lencastre, 2003).

O programa Aprender a compreender torna mas fácil o saber integra textos de tipos e extensão diversos, seguindo-se as orientações propostas por de Sim-Sim e Viana (2007).

\section{FATORES DERIVADOS DO CONTEXTO}

Como nos diz Daniel Pennac (1996, p. 11), "O verbo ler não suporta o imperativo. É uma aversão que compartilha com outros verbos: o verbo 'amar'... o verbo 'sonhar'...”. Não se pode obrigar a ler, pode-se seduzir para a leitura. Esse (difícil) trabalho de sedução exige que no processo de ensino se tenha em linha de conta os interesses dos leitores, a motivação para a leitura e os objetivos de leitura. Motivar para a leitura passa também por criar objetivos de leitura. Curto, Morillo e Teixidó (2000) consideram fundamental estabelecer objetivos para a leitura. Para que ler? O que procura o leitor quando lê? Informação? Conhecimento? Resposta a dúvidas? Orientações? Ou simplesmente fruir e encantar-se com as palavras lidas? Não importa qual o objetivo, o importante é que ele exista e que tenha significado para o leitor.

São frequentes as queixas de pais e professores relativas à desmotivação dos alunos para ler. A motivação dita um maior envolvimento do leitor, mas ela não nasce do nada, pelo que é importante atender ao potencial motivador dos próprios textos. A seleção de textos para ensinar a ler - frequentemente constituída por excertos - não pode perder de vista um segundo objetivo, que é o de alimentar o desejo de ler as obras integrais, nomeadamente quando se trata de obras de literatura infantojuvenil. Para além de se ter atendido ao potencial motivador dos textos (e excertos) selecionados para o programa apresentado neste artigo, não foi efetuada qualquer adaptação neles.

Merece especial destaque, pela relevância que assume no processo de ensino, um conjunto de variáveis que Mosenthal (1989) inclui no fator contexto, a que chama variáveis situacionais. Essas variáveis incluem:

- o organizador de situações (exemplo: o professor);

- a tarefa (conjunto de instruções, perguntas ou atividades) e;

- o cenário (individual, pequeno grupo...).

A maneira como o professor organiza as situações de ensino, nesse caso da leitura (incluindo a motivação, a ativação dos conhecimentos prévios, a seleção de textos), e as atividades propostas (antes, durante e após a leitura) é determinante. Cabe ao professor dinamizar momentos de leitura verdadeiramente orientada, pois é essa orientação estruturada que modelará nos alunos estratégias possíveis para abordar e interrogar o texto.

Quando se pergunta aos professores de diversos níveis de ensino quais as estratégias que utilizam para ensinar a compreender, a resposta é geralmente apenas uma: fazendo perguntas. As perguntas são de facto a estratégia mais usada, mas, por si só, não ensinam a compreender. Além disso, sabe-se que acertar a resposta 
de pergunta não é sinónimo de compreensão. É preciso que elas sejam inteligentemente formuladas para que levem os alunos a entrar nos textos. No programa Aprender a compreender torna mais fácil o saber propõem-se diferentes tipos de tarefas: perguntas com resposta de escolha múltipla, com ou sem pedido de justificação; transcrição de palavras, frases ou expressões; elaboração de respostas curtas; seleção de opções entre várias fornecidas; perguntas de verdadeiro/falso; completamento de frases, ordenação de frases e associação de frases; esquemas; tabelas, resumos e a elaboração de perguntas pelos próprios alunos. A fim de contrariar um comportamento habitual dos alunos, que consiste em ler um texto apenas uma vez, respondendo em virtude da informação que conseguiram reter, propõem-se tarefas que remetem para re-leitura(s) do texto, mostrando a utilidade e/ou a imprescindibilidade dessa estratégia.

No programa, as diferentes tarefas são orientadas no intuito de ajudar os alunos não só a construirem conhecimento, mas também a explicitar a forma como o conseguiram fazer, ou seja, a explicitar os seus raciocínios. $\mathrm{O}$ uso de perguntas orientadas para o produto e de tarefas orientadas para o processo (Quadro 1) permite a partilha (via modelagem) das estratégias metacognitivas usadas pelos diferentes alunos para a resolução dos problemas.

No que concerne aos cenários, ao longo do programa são criados contextos de comunicação nos quais é estimulada a interação entre alunos e entre alunos e professor, permitindo não apenas a produção de respostas, mas também a reflexão sobre o modo como elas foram encontradas e a explicitação da argumentação que as sustenta. Sugere-se, por isso, em um grande número tarefas, que as respostas sejam trabalhadas em grande grupo e por pares de alunos. Quando se propõem respostas individuais, sugere-se o recurso à autocorreção, seguida de justificação e de discussão das opções, nomeadamente quando se trata de perguntas com resposta de escolha múltipla, verdadeiro/falso, ordenação, seleção de várias alternativas ou de completamento.

\section{Quadro 1 - Processo versus produto na formulação de perguntas que promovam a compreensão da leitura}

\begin{tabular}{|l|l|}
\hline \multicolumn{1}{|c|}{$\begin{array}{c}\text { Perguntas orientadas } \\
\text { para o produto }\end{array}$} & \multicolumn{1}{c|}{$\begin{array}{c}\text { Perguntas orientadas } \\
\text { para o processo }\end{array}$} \\
\hline Neste parágrafo o que significa...? & O que te faz dizer que...? \\
\hline Em que lugar decorre a história? & O que precisas de saber para compreender a frase? \\
\hline Como é que o herói resolveu o problema? & O que te permitiu prever o que aconteceu? \\
\hline Por que é que o título foi bem escolhido? & $\begin{array}{l}\text { O que te pode ajudar a encontrar } \\
\text { o sentido da palavra? }\end{array}$ \\
\hline O que podemos concluir sobre a personagem...? & Há palavras novas, para ti, no texto? \\
\hline Como se sentia o...? & O que contribuiu para que gostasses da história? \\
\hline Resume o parágrafo... & O que te levou a dizer que o texto é imaginário? \\
\hline
\end{tabular}

Fonte: baseado em Giasson (2000, p. 300).

Elaboração das autoras. 


\section{FATORES DERIVADOS DO LEITOR}

Nos fatores derivados do leitor são incluídas variáveis como as estruturas cognitivas e afetivas do sujeito e os processos de leitura que este ativa (Giasson, 2000,2005). Ao ler, o leitor ativa um conjunto de conhecimentos e convoca os processos e estratégias disponíveis para extrair sentido. Esses processos e estratégias, que vão sendo aprendidos ao longo da experiência como leitor, nem sempre se mostram os mais adequados, precisamente porque não foram alvo de ensino explícito. Quer a falta de conhecimentos prévios que permitam integrar a informação nova na informação pré-existente, quer o uso de processos e estratégias inadequados que resultam em problemas de compreensão.

Já no que concerne aos conhecimentos prévios dos leitores, podemos estar diante de vários tipos de situações:

- os alunos possuem os conhecimentos prévios requeridos e os utilizam?

- os alunos possuem os conhecimentos prévios, porém não os utilizam?

- os alunos têm um conhecimento cultural alargado, mas não dispõem dos conhecimentos específicos requeridos por um determinado texto?

- os alunos possuem conhecimentos errados que interferem na compreensão?

- os alunos têm conhecimentos reduzidos (ou nulos)? (Rumelhart, 1980; Solé, 1992).

No programa Aprender a compreender torna mais fácil o saber, quando se considera que os textos selecionados requerem conhecimentos que podem não fazer parte do repertório dos alunos, propõem-se, previamente, atividades relacionadas com o conteúdo específico do texto e centradas nos conhecimentos necessários à sua compreensão.

Dentro desse fator merecem ainda especial atenção as competências linguísticas dos leitores (McGuinness, 2005). Se a posse de um amplo vocabulário e o conhecimento de estruturas sintáticas diversas facilitam a aprendizagem da leitura (McGuinness, 2006), não é menos certo que é essencialmente pela leitura que aprendemos palavras novas.

\section{ESTRATÉGIAS PARA ORIENTAR OS ALUNOS NO PROCESSO DE COMPREENSÃO}

Atendendo ao que foi dito no ponto anterior, e atendendo a que o programa Aprender a compreender torna mais fácil o saber pretende munir o leitor de um conjunto de ferramentas para compreender os textos que lê, todas as atividades propostas têm subjacentes duas linhas de força:

1. a explicitação do tipo de processo a convocar e;

2. a promoção de estratégias de metacompreensão.

\section{EXPLICITAÇÃO DO TIPO DE PROCESSO A CONVOCAR}

Na literatura da especialidade encontram-se diferentes classificações dos subprocessos envolvidos na compreensão da leitura (Barrett, 1976; Català et al., 2001; Giasson, 
2005). No Quadro 2 apresenta-se uma síntese das propostas de Barrett (1976) e Català e colaboradores (2001), que explicitam de forma simples e clara o que está na base de cada processo e facilitam o seu relacionamento com objetivos de aprendizagem.

Para ajudar os alunos a identificar o processo que está subjacente à pergunta ou à tarefa proposta e, simultaneamente, desenvolver estratégias de metacompreensão, foram concebidas seis personagens que constituem a Família Compreensão (Figura 1).

O conceito de família remete para a sua interdependência e complementaridade. Os seis personagens - Vicente Inteligente, Juvenal Literal, Durval Inferencial, Conceição Reorganização, Francisca Crítica e Gustavo Significado —, cujas imagens

\section{Quadro 2 - Síntese da taxonomia da compreensão leitora}

\begin{tabular}{|l|l|}
\hline Tipo de & \multicolumn{1}{c|}{$\quad$ Definição e Operacionalização } \\
\hline \multirow{5}{*}{$\begin{array}{l}\text { Compreensão } \\
\text { literal }\end{array}$} & $\begin{array}{l}\text { Reconhecimento de toda a informação explicitamente incluída em um texto: } \\
\text { - Reconhecimento de ideias principais } \\
\text { - Reconhecimento de uma sequência }\end{array}$ \\
\hline \multirow{5}{*}{ - Reconhecimento de detalhes } \\
Reorganização
\end{tabular}

Fonte: Català et al. (2001).

Elaboração dos autores. 
e caraterização são apresentadas no Anexo 1, personificam respetivamente os processos de metacompreensão, compreensão literal, compreensão inferencial, reorganização da informação e compreensão crítica e os processos lexicais (vocabulário).

Esses personagens, com papéis diferenciados, constituem um eficaz recurso lúdico-didático que permite concretizar (e explicitar) processos abstratos e promover o uso de estratégias metacognitivas. Cada um partilha com o leitor as estratégias que usa para ser eficiente. No Quadro 3 apresenta-se uma síntese das diferentes estratégias a usar, tendo como base os três momentos geralmente considerados na investigação: antes, durante e após a leitura (Giasson, 2005). Essa sistematização, elaborada valendo-se da revisão de vários documentos (Giasson, 2000; Irwin, 1986; Sim-Sim, Duarte e Micaelo, 2007), serviu de base para a elaboração das diferentes tarefas que vão sendo propostas ao longo do programa.

\section{ANÁLISE DE TAREFAS}

Após a apresentação da Família Compreensão, segue-se a análise de tarefas, para a qual vão sendo convocadas os diferentes personagens que a constituem. A descrição que cada personagem faz de si próprio pretende modelar atitudes e modos de ação (Figura 2).

Se os alunos conseguem identificar a personagem a quem pedir ajuda, estão, afinal, a identificar o processo correspondente. Assim sendo, análise de tarefas é uma etapa crucial. Para cada texto selecionado propõe-se um conjunto de tarefas que se organiza numa sequência didática cujo objetivo é ajudar os alunos a extrair (e a construir) significado(s) nos textos lidos. Essa análise é efetuada, de forma

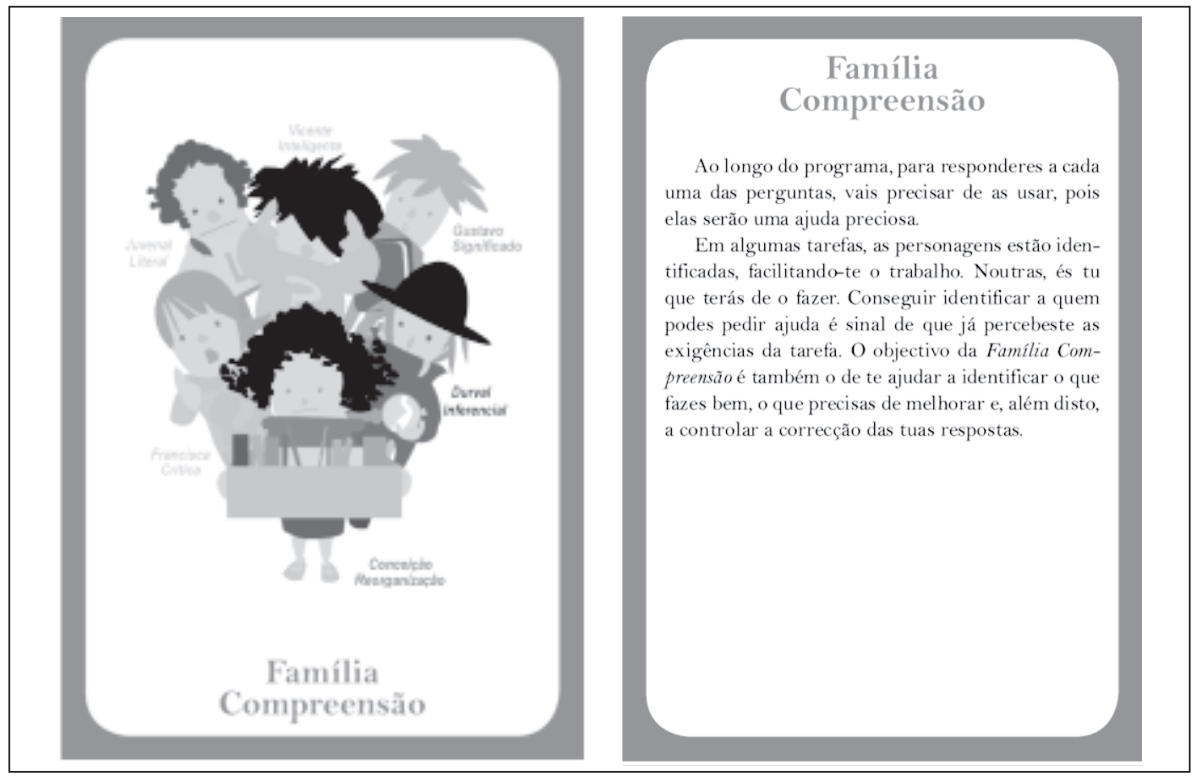

Figura 1 - Descrição da Família Compreensão

Fonte: Viana et al. (2010b, p. 247-248). 
explícita, no início do programa, pelos professores e alunos, mas também por meio da mediação do personagem Vicente Inteligente, exemplificada na Figura 3.

Cada proposta de trabalho visa ajudar os alunos a adotar um percurso metódico (e estratégico) de abordagem dos textos. Pretende-se que:

- compreendam o que é solicitado;

- identifiquem a(s) estratégia(s) mais adequada(s) para responder à solicitação;

- ativem os processos cognitivos e linguísticos necessários;

- controlem as respostas produzidas, desenvolvendo estratégias de verificação.

\section{A LEITURA ORIENTADA DOS TEXTOS}

Depois de apresentada a Família Compreensão e da análise do tipo e exigências das diferentes tarefas, seguem-se a leitura e a análise dos vários textos de acordo com a sequência básica apresentada na Figura 4.

\section{Quadro 3 - Classificação de estratégias dirigidas para o ensino da compreensão em virtude dos momentos de leitura}

\begin{tabular}{|c|c|}
\hline 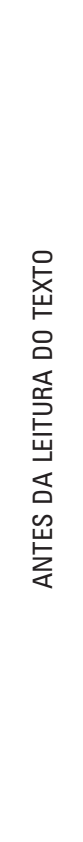 & $\begin{array}{l}\text { - Dar informações sobre o texto. } \\
\text { - Eormular perguntas sobre o texto. } \\
\text { os alunos efetuarem previsões sobre ele. } \\
\text { - Explorar as ilustrações e utilizá-las de modo que possa levar } \\
\text { os alunos a efetuarem previsões sobre o texto. } \\
\text { - Identificar e explorar vocabulário/expressões que possam surgir no texto } \\
\text { e que se prevê poderem não ser do conhecimento dos alunos. } \\
\text { - Ativar (geralmente por meio de debate oral) os conhecimentos } \\
\text { prévios dos alunos sobre o tema abordado no texto. } \\
\text { - Explicar palavras ou aspetos-chaves do texto. } \\
\text { - Relacionar o tema do texto com conhecimentos que os alunos já possuem. } \\
\text { - Suscitar a apresentação de dúvidas/comentários dos alunos sobre o texto. } \\
\text { - Incentivar os alunos a folhearem os livros antes de iniciarem a sua } \\
\text { leitura e debater com eles os dados que recolheram. } \\
\text { - Incentivar os alunos a analisarem títulos, imagens, palavras, frases destacadas } \\
\text { ou outras marcas que apareçam e debater com eles o seu objetivo. } \\
\text { - Dialogar com os alunos sobre os autores dos textos, relembrando, } \\
\text { por exemplo, outros textos já lidos do mesmo autor. } \\
\text { - Ajudar os alunos a definirem os objetivos de leitura. } \\
\text { - Fornecer instruções detalhadas sobre como ler um texto em } \\
\text { virtude de suas caraterísticas e finalidades da leitura. } \\
\text { - Outros (por exemplo, orientar a atenção do aluno para a localização } \\
\text { de determinado tipo de informação fornecida pelo texto). }\end{array}$ \\
\hline 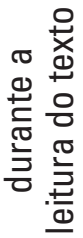 & $\begin{array}{l}\text { - Orientar os alunos para destacarem palavras/expressões } \\
\text { eventualmente difíceis de compreender. } \\
\text { - Orientar os alunos para destacarem trechos do texto que não compreendem. } \\
\text { - Incentivar os alunos a efetuarem previsões sobre a continuação do } \\
\text { tema/narrativa, após a conclusão de um trecho predefinido. } \\
\text { - Instruir os alunos para elaborar perguntas a que poderá } \\
\text { ser dada resposta em momento posterior. }\end{array}$ \\
\hline
\end{tabular}




\section{Quadro 3-Continuação}

\begin{tabular}{|c|c|}
\hline 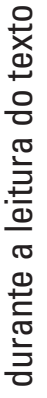 & $\begin{array}{l}\text { - Incentivar os alunos a confrontarem previsões efetuadas antes de iniciarem } \\
\text { a leitura com a informação recolhida à medida que leem o texto. } \\
\text { - Interromper a leitura em parágrafos ou palavras predeterminadas e } \\
\text { formular perguntas a que os alunos devem responder de imediato. } \\
\text { - Fornecer cópias do texto com anotações na margem, chamando atenção para os } \\
\text { aspetos mais relevantes que devem ser lembrados em momentos posteriores. } \\
\text { - Interromper a leitura em momentos estratégicos e } \\
\text { convidar os alunos a reagirem ao que leram. } \\
\text { - Incentivar os alunos a recorrerem ao contexto para descobrirem } \\
\text { o significado de palavras e expressões não conhecidas. } \\
\text { - Incentivar o confronto entre texto e ilustração à medida que os alunos leem o texto. }\end{array}$ \\
\hline 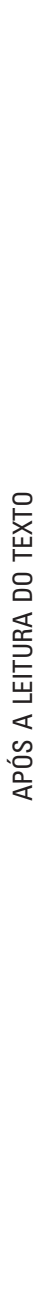 & 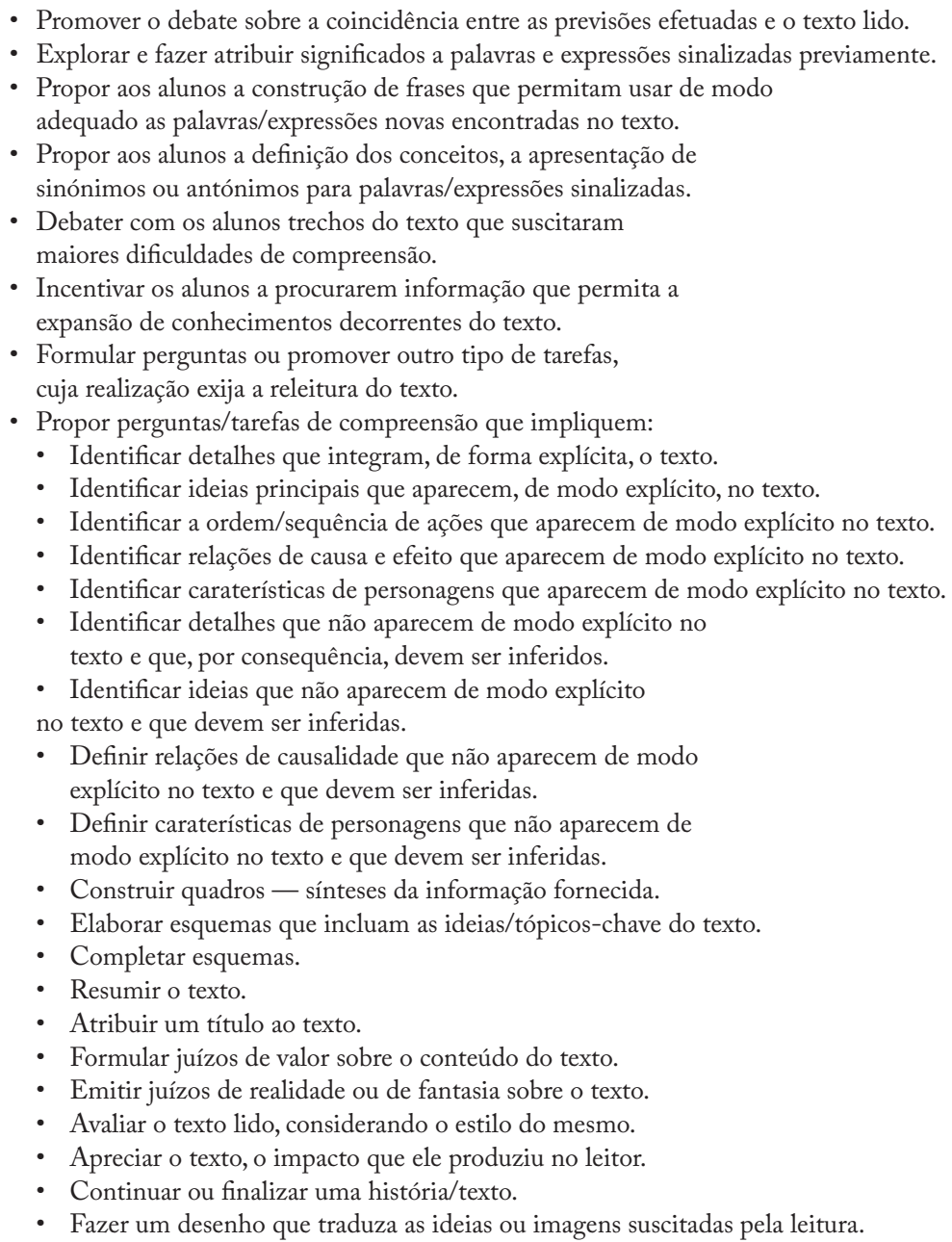 \\
\hline
\end{tabular}

Fonte: Banco de dados da pesquisa.

Elaboração das autoras. 
Após a leitura, seguem-se a análise do tipo de texto e a sua exploração, que inclui a classificação do processo, por parte do aluno - traduzido na identificação da personagem da Familia Compreensão. As primeiras tarefas propostas são acom-

Olá! O meu nome é DURVAL INFERENCIAL. A minha família chama-me detective, porque adoro enigmas. O meu trabalho é muito minucioso, com várias etapas que têm de ser seguidas com rigor... e sem pressas. Primeiro, há que pensar muito bem no problema que tenho de desvendar. Só depois procuro as pistas que o texto me pode dar. Como qualquer detective, preciso de ajudas. O Gustavo Significado e a Conceição Reorganização são os meus "ajudantes de campo". Junto pistas e ajudas, penso, estabeleço relações e conexões e outros ões e... eureka!... encontro as soluções. Parece fácil? Parece, mas não é. Muitas vezes as pistas que estão no texto não são suficientes e eu tenho de as juntar a outros conhecimentos anteriores. Outras vezes ainda preciso de recorrer a "especialistas" para encontrar a tal informação de que necessito para resolver os mistérios. O meu lema é: - "Pensar e saber é o truque para tudo resolver!"

Figura 2 - Apresentação do personagem Durval Inferencial Fonte: Viana et al. (2010b, p. 29).

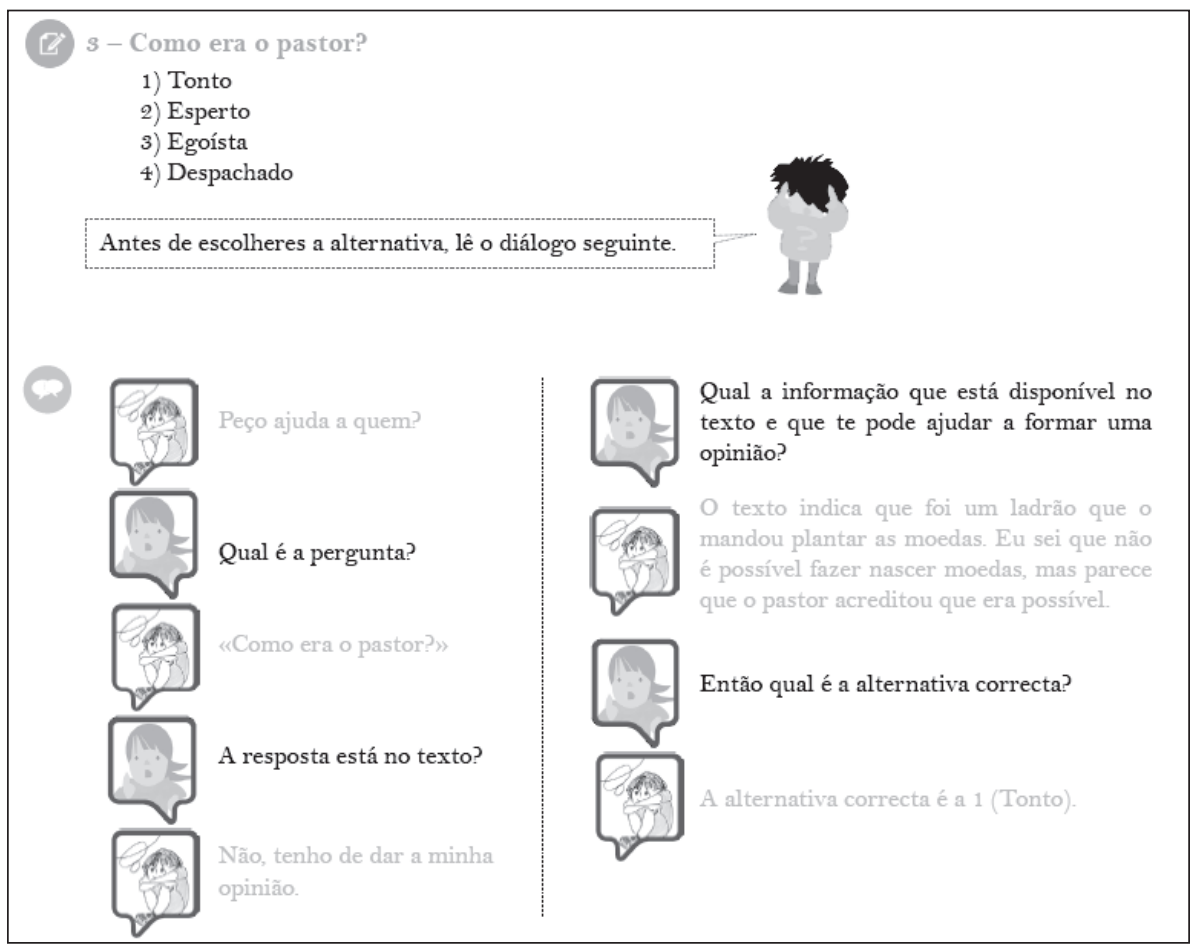

Figura 3 - Exemplo de um diálogo entre uma personagem e o "aluno pensador" para análise de tarefa Fonte: Viana et al. (2010b, p. 33). 
panhadas da imagem da Família Compreensão, que deve ser convocada (Figura 5), passando depois a solicitar-se a sua identificação (Figura 6).

\section{SUGESTÕES AOS PROFESSORES}

Em cada um dos textos que integram o programa são incluídos comentários e sugestões que podem contemplar vários aspetos:

- pesquisa prévia de informação relevante para a compreensão do texto;

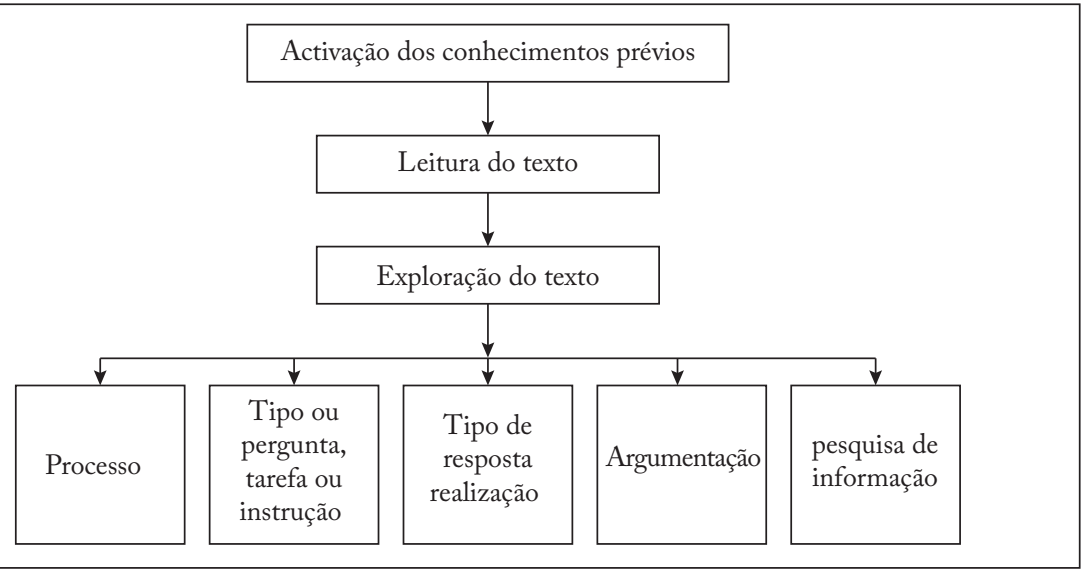

Figura 4 - Sequência básica de exploração do texto

Fonte: Viana et al. (2010b, p. 22).

5 - Qual achas que seria a solução do curandeiro? Selecciona a alternativa correcta.

1) Fazer desaparecer o dedo mindinho.

2) Cortar o dedo do Pedro.

3) Pôr uma pomada milagrosa.

4) Não tinha nenhuma solução.

Figura 5 - Pergunta com resposta de escolha múltipla, incluindo a imagem de personagem da Família Compreensão a convocar

Fonte: Viana et al. (2010b, p. 49).

1 - Selecciona a alternativa correcta para completar a frase.

A aranha ralhou com o bichinho-da-seda porque...

1) ele fez uma teia completa.

2) tinha inveja dos casulos que ele fazia.

3) ele estava sobre a folha da amoreira.

4) ele estava a demorar muito tempo a fazer o casulo.

Escreve aqui o nome da personagem da Família Compreensão

Figura 6 - Pergunta com resposta de escolha múltipla, incluindo solicitação para identificação de personagem da Família Compreensão a convocarç

Fonte: Viana et al. (2010b, p. 52). 
- antecipação de algumas dificuldades decorrentes do conteúdo do texto ou do tipo de suporte;

- expansão de algumas atividades ou;

- propostas de escrita (Figura 7).

\section{AVALIAR PARA MONITORIZAR}

No decurso do programa existem sete momentos de avaliação (Figura 8).

Cada uma das perguntas incluídas nas seis ${ }^{3}$ provas de avaliação foi classificada de acordo com os processos que são ensinados de modo explícito ao longo do programa. A fim de facilitar o cálculo do desempenho de cada aluno e do grupo-turma, é disponibilizada uma folha de cálculo Excel que permite o registo da pontuação de cada aluno (por prova) e a geração de gráficos de desempenho (individual e de

O texto que se segue é o primeiro texto informativo proposto no programa, razão pela qual se optou por um texto curto e de vocabulário acessível. A palavra "Grânulos" aparece assinalada com um asterisco, que remete para a consulta de um glossário, recurso que é, pela primeira vez, introduzido no programa. Recomenda-se que os alunos sejam ensinados a verificar, antes de iniciarem a leitura, se esta informação está disponível. Caso esteja, é aconselhável que a leiam, antes de procederem à leitura do texto.

Em alguns casos, as definições presentes nos glossários e nos dicionários incluem mais do que um sentido, pelo que, ao lerem o texto, os alunos deverão ser incentivados a procurar qual é o mais adequado.

Classificação e extensão do texto: Informativo, 97 palavras.

Proposta de operacionalização:

- Organização do grupo de alunos: Trabalho individual.

- Modalidade de leitura do texto: Leitura silenciosa.

- Modalidade de leitura das instruções: Leitura silenciosa.

- Identificação das personagens da Família Compreensão: Identificação a efectuar pelos alunos.

- Realização das actividades: Escrita; registo individual no caderno do aluno.

- Correcção: Auto-correcção.

Figura 7 - Exemplo de sugestão de operacionalização das tarefas

Fonte: Viana et al. (2010b, p. 54).

Abre o livro na página 127 e responde à Prova de Aferição de 2004 (Avaliação 6).

A palavra "avaliação" já não te põe nervoso, pois não? Concentra-te, respira fundo e... ao trabalho!

Figura 8 - Exemplo de convite para um momento de avaliação

Fonte: Viana et al. (2010a, p. 72).

3 São sete os momentos de avaliação, mas apenas são usadas seis provas, dado que a avaliação inicial e a avaliação final são efetuadas com a mesma prova. 
grupo). Como essa folha de cálculo inclui o número da tarefa e o seu processo avaliado, podem ser calculados valores parciais para cada um dos processos e gerados gráficos e desempenho individuais por processo. Assim, um aluno pode verificar, por exemplo, que as tarefas em que experimenta mais dificuldades são as que remetem para processos inferenciais (tarefas nas quais é o personagem Durval Inferencial quem presta ajuda).

\section{PROMOÇÃO DE ESTRATÉGIAS DE METACOMPREENSÃO}

Para além de munir o leitor de um conjunto de ferramentas para compreender os textos que lê, pretendia-se também ajudá-lo a monitorizar a sua compreensão e ativar recursos quando surgem dificuldades, isto é, a desenvolver competências de gestão da compreensão (Geninet et al.,2009). São elas que permitem monitorizar falhas na compreensão e ajustar estratégias de correção (Giasson, 2005; Irwin,1986; Sánchez Miguel, 2002,2010).

No estudo da metacompreensão encontram-se duas correntes. A primeira (Flavell, 1981) centra-se nos conhecimentos que um leitor possui acerca das competências, e estratégias e recursos necessários para ter sucesso em uma atividade de leitura. Esse conhecimento subdivide-se habitualmente em três vertentes:

1. o conhecimento do leitor acerca dos seus recursos e limites cognitivos, dos seus interesses e da sua motivação;

2. o conhecimento sobre as exigências da atividade de leitura e;

3. o conhecimento sobre as estratégias que pode ativar para resolver um problema de leitura (Giasson, 2000).

A segunda centra-se na aptidão para utilizar processos de autorregulação (Shaughnessy, Veenman e Kleyn-Kennedy, 2008). Perante um problema, o leitor utiliza as estratégias que lhe permitem resolvê-lo. Esses processos de gestão podem assumir diferentes aspetos:

- saber quando compreendemos ou não compreendemos;

- saber o que compreendemos e o que não compreendemos;

- saber do que precisamos para compreender;

- saber que podemos fazer algo quando não compreendemos (Brown, 1980).

Os maus leitores e os leitores principiantes são, no geral, leitores não estratégicos. Os leitores eficientes utilizam diferentes estratégias para lidar com as dificuldades encontradas, nomeadamente:

- subestimar a incoerência: o leitor opta por ignorar o erro, desvalorizando o elemento não considerado como imprescindível para a compreensão do texto;

- suspender o juízo se o texto contém informação que permita reorientar o texto;

- procurar explicações alternativas, abandonando as hipóteses formuladas anteriormente;

- retroceder na leitura ou explorar partes do texto em um esforço para situar o elemento discordante (exemplo: releitura de uma palavra, uso do 
contexto imediato ou de informações anteriores, atender a marcas organizativas, como o título, o início do parágrafo);

- procurar a solução no exterior do texto, com consulta a outras pessoas, ao dicionário e a outros livros (Giasson, 2000).

As tarefas propostas no programa Aprender a compreender torna mais fácil o saber foram desenhadas para promover o desenvolvimento de estratégias para o leitor lidar com as dificuldades e os desafios que cada texto (e tarefa) vai apresentando. A metacompreensão é, assim, promovida por meio de quatro estratégias:

1. análise das exigências de diferentes tarefas;

2. explicitação e análise dos processos de compreensão associados a cada pergunta/tarefa;

3. inclusão de perguntas dirigidas aos processos usados na elaboração das respostas e;

4. apresentação de sugestões por parte do personagem Vicente Inteligente (Figuras 9 e 10).

\section{ESTUDO DO IMPACTO DO PROGRAMA}

Neste estudo pretende-se avaliar as mudanças no desempenho em compreensão da leitura de alunos do $4^{\circ}$ ano de escolaridade que participaram de um programa de desenvolvimento da compreensão da leitura.

\begin{tabular}{|l|l|l|}
\hline \multicolumn{2}{|c|}{$\begin{array}{l}\text { 4-De acordo com as informações do texto que leste, assinala com X, em cada uma das } \\
\text { respectivas colunas, se as afirmações são Verdadeiras (coluna V) ou Falsas (coluna F). }\end{array}$} \\
\hline 1 & Mariana, de cinco anos, e Pedro, de sete, já têm idade para jogar o Loto Animais Bebés. & V F \\
\hline 2 & Só podem jogar duas equipas, cada uma com quatro crianças. & \\
\hline 3 & As fichas são postas em cima da mesa, baralhadas. & \\
\hline 4 & Quem pede uma ficha tem de dizer o nome do animal bebé. & \\
\hline & $\begin{array}{l}\text { Esta é uma actividade em que te é pedida uma decisão sobre se as afirma- } \\
\text { ções são verdadeiras ou falsas. Esta informação pode estar explícita no texto } \\
\text { - e é o Juvenal Literal que trabalha -, ou podes ter de a descobrir. Neste caso, } \\
\text { terás de pedir ajuda ao Durval Inferencial. } \\
\text { Qualquer que seja a personagem da Família Compreensão a dar-te aju- } \\
\text { da, não te precipites. Antes de marcares a tua resposta, faz uma classifica- } \\
\text { ção provisória, a lápis. Justifica, para ti próprio, porque a escolheste, mesmo } \\
\text { quando não te pedem que o faças. Relê o texto, confirma se a tua resposta } \\
\text { provisória estava correcta ou faz as correcções necessárias. }\end{array}$ \\
\hline
\end{tabular}

Figura 9 - Exemplo de análise de uma tarefa

Fonte: Viana et al. (2010b, p. 86). 


\section{MÉTODO}

\section{PARTICIPANTES}

Todos os participantes do estudo eram alunos de escolas do Concelho de Vila Nova de Famalicão, localizado na zona Norte de Portugal.

Participaram 1.142 alunos do $4^{\circ}$ ano de escolaridade do $1^{\circ}$ ciclo do ensino básico, dos quais, $562(49,2 \%)$ eram do sexo masculino e 580 (50,8\%), do sexo feminino. As idades variavam entre 7 e 11 anos (média = 8,85 anos; desvio-padrão $=0,52$ ). Estiveram envolvidos na implementação do programa 76 professores, provenientes de 52 escolas.

\section{INSTRUMENTOS}

\section{TCL - Teste de compreensão da leitura (Cadime, Ribeiro e Viana, 2012)}

OTCL é um teste de avaliação da compreensão da leitura destinado a avaliar a compreensão literal e inferencial, a reorganização de informação e a compreensão crítica. É destinado a alunos do $2^{\circ}$ ao $4^{\circ}$ ano de escolaridade. O texto usado, inédito, foi elaborado por uma escritora de literatura infantojuvenil, tem o formato de um diário e integra sequências de textos de diferentes tipos (narrativo, informativo, poético e prescritivo).

Em cada item é apresentada uma pergunta e quatro alternativas de resposta, das quais apenas uma é correta. A sua construção foi efetuada no quadro da teoria da resposta ao item. As versões destinadas a cada ano foram sujeitas a um processo de equalização permitindo comparar a evolução nos desempenhos dos sujeitos ao nível da compreensão da leitura. Os itens apresentam de Infit e Outfit inferiores a 1,50. Os valores dos coefientes de Kuder-Richardson, Person Separation Reliability e Item Separation Reliability variam, entre .70 e .98 , considerando os três anos a que a prova se destina. $\mathrm{O}$ estudo da validade de construto, efetuada com recurso à análise fatorial confirmatória, indicam para cada uma das versões que os itens saturam num único fator. $\mathrm{O}$ valor de qui-quadrado foi estatisticamente significativo nos

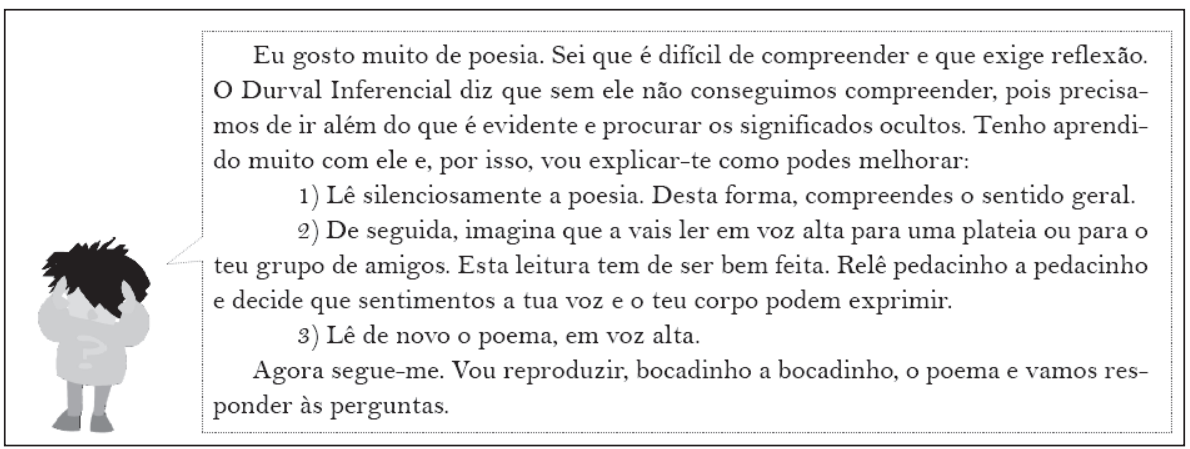

Figura 10 - Sugestão de estratégia por parte do personagem Vicente Inteligente Fonte: Viana et al. (2010b, p. 40). 
três modelos $\left(\mathrm{c}^{2}{ }_{(405)}=471,69, \mathrm{p}<0,05 ; \mathrm{c}^{2}{ }_{(405)}=484,11, \mathrm{p}<0,05 ; \mathrm{c}^{2}{ }_{(405)}=473,05, \mathrm{p}<0,05\right)$, o que poderá ser explicado pela dimensão amostral (Byrne, 2011).

Em cada uma das três versões, os índices absolutos apresentam valores inferiores a 0,05, no caso do RMSEA (Root Mean Square Error of Approximation) $\left(\mathrm{RMSEA}_{\mathrm{TCL}-2}=0,021 ; \mathrm{RMSEA}_{\mathrm{TCL}-3}=0,02 ; \mathrm{RMSEA}_{\mathrm{TCL}-4}=0,02\right)$, e inferiores a 1,0 , no caso do WRMR (Weighted Root Mean Square Residual) (WRMR TCL-2 $_{2}=0,96$; $\left.\mathrm{WRMR}_{\mathrm{TCL}-3}=0,95 ; \mathrm{WRMR}_{\mathrm{TCL}-4}=0,93\right)$. Os índices incrementais são elevados nos três modelos superando o valor mínimo de 0,90 , tanto no caso do CFI (Comparative Fit Index) como do TLI (Tucker-Lewis Index). Correlações moderadas foram obtidas entre os resultados no TCL e a PRP (Prova de reconhecimento de palavras) (Viana e Ribeiro, 2010) nos três anos de escolaridade ( $2^{\circ}$ ano: $\mathrm{r}=.39$; $3^{\circ}$ ano: $\mathrm{r}=.36$; $4^{\circ}$ ano: $r=.41$ ). As correlações com a prova Avaliação da Compreensão da Leitura (Català et al., 2001; adaptação portuguesa de Mendonça, 2008) foram de .26 ( $2^{\circ}$ ano), .66 ( $\left.3^{\circ} \mathrm{ano}\right)$ e .73 (4o ano). Finalmente, as correlações com os exames nacionais de língua portuguesa (compreensão) foram de $.47, .60$ e .56, respetivamente.

\section{PRP - Prova de reconhecimento de palavras (Viana e Ribeiro, 2010)}

A PRP é uma prova de reconhecimento de palavras regulares, destinada a avaliar a velocidade e a precisão de leitura com alunos do $1^{\circ}$ ao $4^{\circ}$ ano do $1^{\circ}$ ciclo do ensino básico. É constituída por quarenta itens (mais três de treino). Em cada item é apresentada uma imagem, seguida de quatro palavras, de entre as quais os sujeitos têm de selecionar a que nomeia a imagem respetiva. Quanto à extensão, 20 palavras são de 2 sílabas e 20 são de 3 sílabas. Quanto ao número de vizinhas ortográficas, em 5 itens são apresentadas 3 vizinhas da palavra-alvo, em 16 itens são apresentadas 2 vizinhas das palavras-alvo, em 13 itens é apenas apresentada uma vizinha e em 6 itens apenas são apresentadas palavras com proximidade ortográfica. Nos quatro anos de escolaridade, o coeficiente alpha de Cronbach situou-se em .95, .95, .93 e .84. Os resultados da análise factorial confirmatória indicam que todos os itens saturam num único fator. $\mathrm{O}$ valor de qui-quadrado é estatisticamente significativo $\left(\mathrm{c}^{2}=335,248\right.$; $\mathrm{gl}=51 ; \mathrm{p}<0,001)$, os outros índices de ajustamento global são elevados (CFI =.979; TLI =.989), situando-se acima dos valores de referência (Hu e Bentler, 1999). As correlações com a avaliação da leitura realizada pelos professores varia entre .62 e .84.

\section{Prova de aferição de língua portuguesa do $1^{\circ}$ ciclo do ensino básico de $2012^{4}$}

As provas de aferição de língua portuguesa são da responsabilidade do Ministério da Educação e avaliam a compreensão da leitura (parte 1), o conhecimento explícito da língua (parte 2) e a escrita (parte 3). Na primeira parte são apresentados dois textos seguindo-se um conjunto de perguntas que avaliam os níveis de compreensão na leitura. $\mathrm{O}$ formato de tarefas nessa primeira parte é diverso, incluindo perguntas de resposta aberta, completamento, escolha múltipla, verdadeiro/falso e de ordenação. A prova do $1^{\circ}$ ciclo do ensino básico é realizada em nível nacional

4 Prova e critérios de codificação disponíveis para consulta em: <http://bi.iave.pt/exames/ download/PAF-1_LP_1_CC1_2012.pdf?id=4846>. Acesso em: 7 nov. 2017. 
por todos os alunos do $4^{\circ}$ ano de escolaridade, no final do ano letivo. São obtidos resultados para o total da prova, bem como para cada uma das partes que a compõem, expressos em uma escala de A (= Excelente) a E (= Não satisfaz).

\section{PROCEDIMENTOS}

A implementação do programa Aprender a compreender torna mais fácil o saber (Viana et al., 2010a) foi organizada no âmbito de um processo de cooperação entre a Universidade do Minho, a Câmara Municipal de Vila Nova de Famalicão, os Diretores dos Agrupamentos de Escolas do concelho e o Centro de Formação Associação de Escolas de Vila Nova de Famalicão.

A implementação do programa foi efetuada individualmente por cada professor titular de turma. O acompanhamento da implementação do programa foi efectuado no âmbito de uma ação de formação contínua para professores. As sessões de formação eram coordenadas pelas autoras do programa, tendo sido realizadas com periodicidade mensal ao longo do ano letivo. Nas sessões iniciais foram analisados os racionais teóricos adoptados na elaboração do programa, a organização e opções tomadas e ainda os materiais de apoio disponíveis online (Viana et al., 2010b). Foi ainda planificada e calendarizada a implementação do programa. Nas restantes sessões, os professores partilhavam o trabalho realizado e apresentavam os resultados obtidos pelos alunos nas várias provas de avaliação da compreensão da leitura incluídas no programa e que visavam à monitorização das mudanças no desempenho dos alunos. Entre sessões, questões e dúvidas eram esclarecidas por correio eletrónico entre os professores e as autoras do programa.

Os materiais necessários para a implementação do programa, especificamente o livro destinado aos alunos (Viana et al., 2010a), foram disponibilizados gratuitamente a todos os alunos pela Câmara Municipal de Vila Nova de Famalicão. A articulação entre os vários parceiros envolvidos era assegurada pelos serviços educativos da Câmara Municipal (prefeitura).

$\mathrm{Na}$ avaliação dos efeitos do programa, recorreu-se a um delineamento de grupo único com dois momentos de avaliação: pré e pós-teste. O TCL foi aplicado no pré e no pós-teste e a PRP foi administrada apenas no pré-teste. Os resultados nas provas de aferição foram obtidos no final do ano letivo, quando a aplicação do programa havia já terminado.

\section{ANÁLISES ESTATÍSTICAS}

Em primeiro lugar, analisaram-se as diferenças médias de desempenho entre o pré e o pós-teste no desempenho em compreensão da leitura, tendo-se, de seguida, analisado a estabilidade de resultados ao longo dos dois momentos de avaliação.

Para testar a mudança entre os dois momentos no tempo, recorreu-se ao teste $t$ para amostras emparelhadas e calculou-se a magnitude do efeito por meio de um coeficiente $r$. De seguida, realizou-se uma análise de covariância para metidas repetidas, tomando o reconhecimento de palavras como covariável na análise da mudança entre o pré e o pós-teste em nível de compreensão. 
$\mathrm{Na}$ análise da estabilidade da mudança, calculou-se um coeficiente de correlação entre os resultados obtidos nos dois momentos de avaliação, a fim de verificar a percentagem de variância de resultados encontrados no pós-teste, que é em virtude dos resultados obtidos no pré-teste. Calculou-se, ainda, o coeficiente da correlação intraclasse para testar em que medida os sujeitos, embora possam melhorar o seu desempenho, mantêm posições relativas no seio do grupo. A fim de observar as mudanças individuais na compreensão entre o pré e o pós-teste, converteram-se os totais obtidos pelos alunos no TCL em cinco classes percentílicas: Classe 1: resultados do percentil 0 ao percentil 25; Classe 2: resultados situados entre o percentil 26 e o percentil 50; Classe 3: resultados situados entre o percentil 51 e o percentil 75; Classe 4: resultados entre o percentil 76 e o percentil 90; Classe 5: resultados superiores ao percentil 90. Elaborou-se, de seguida, uma tabela de contingência para representar as mudanças de classe entre os dois momentos de avaliação. Em uma última fase de análise de resultados, calcularam-se as frequências de resultados dos participantes na prova de aferição, comparando-os com os resultados nacionais.

Todos os procedimentos foram efetuados com recurso ao Statistical Package for the Social Sciences (SPSS), versão 20.0.

\section{RESULTADOS}

\section{MUDANÇAS AO LONGO DO TEMPO NO DESEMPENHO EM COMPREENSÃO DA LEITURA}

No Quadro 4 é apresentada a estatística descritiva para os resultados nas provas de compreensão da leitura e de reconhecimento de palavras nos dois momentos de avaliação.

Observou-se um aumento nas médias de compreensão da leitura entre o pré e o pós-teste. Os valores de dispersão de resultados mantiveram-se semelhantes entre os dois momentos.

Nos testes de aderência à normalidade dos resultados em compreensão da leitura, obtiveram-se coeficientes estatisticamente significativos tanto para os resultados do pré-teste (Kolmogorov-Smirnov $=0,065 ; \mathrm{p}<.001$ ) e do pós-teste (Kolmogorov-Smirnov = 0,060; $\mathrm{p}<.001)$, apontando desvios à normalidade. No entanto, é possível que esses resultados sejam amplamente influenciados pelo tamanho

Quadro 4 - Estatística descritiva dos resultados no TCL e PRP nos dois momentos de avaliação

\begin{tabular}{|l|c|c|c|c|c|}
\hline Variáveis & Amplitude & Média & DP & Assimetria & Curtose \\
\hline Compreensão (pré-teste) & $0-28$ & 13,84 & 4.938 & 0,105 & $-0,526$ \\
\hline Compreensão (pós-teste) & $4-29$ & 17,50 & 4.961 & $-0,216$ & $-0,455$ \\
\hline Reconhecimento de palavras & $0-40$ & 23,30 & 8.474 & 0,295 & $-0,548$ \\
\hline
\end{tabular}

Nota: DP (desvio-padrão).

Fonte: Banco de dados da pesquisa.

Elaboração das autoras. 
da amostra (Field, 2009). Os Gráficos 1 e 2 representam os quartis e os valores extremos das distribuições de resultados no pré e pós-teste.

A observação dos dois diagramas sugere que ambas as distribuições são simétricas, com a mediana a situar-se a aproximadamente à mesma distância do $1^{\circ} \mathrm{e}$ do $3^{\circ}$ quartil. Embora no pré-teste se tenha detectado a existência de dois outliers no nível superior da distribuição, estes não parecem afectar os valores da distribuição de resultados. Perante o elevado tamanho da amostra e tendo em conta as representações dos Gráficos 1 e 2 e os baixos valores de assimetria e curtose (Quadro 4),

\section{Gráfico 1 - Diagrama de extremos e quartis para os resultados em compreensão no pré-teste}

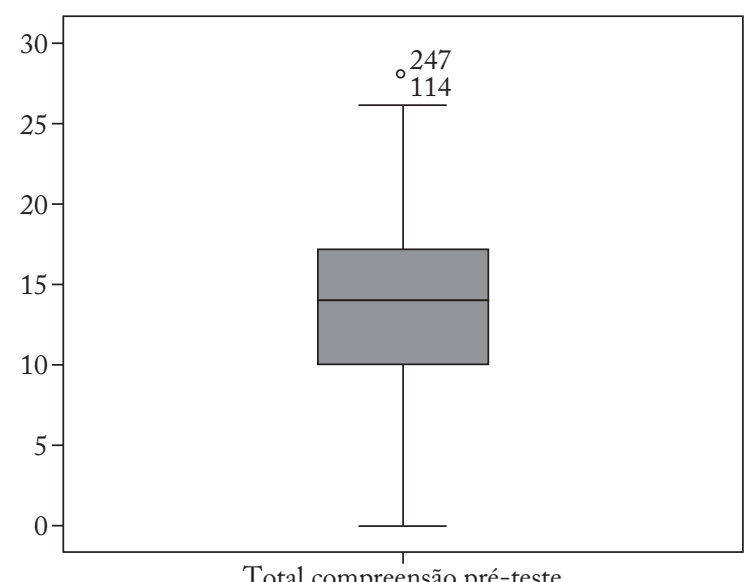

Fonte: Banco de dados da pesquisa.

Elaboração das autoras.

Gráfico 2-Diagrama de extremos e quartis para os resultados em compreensão no pós-teste

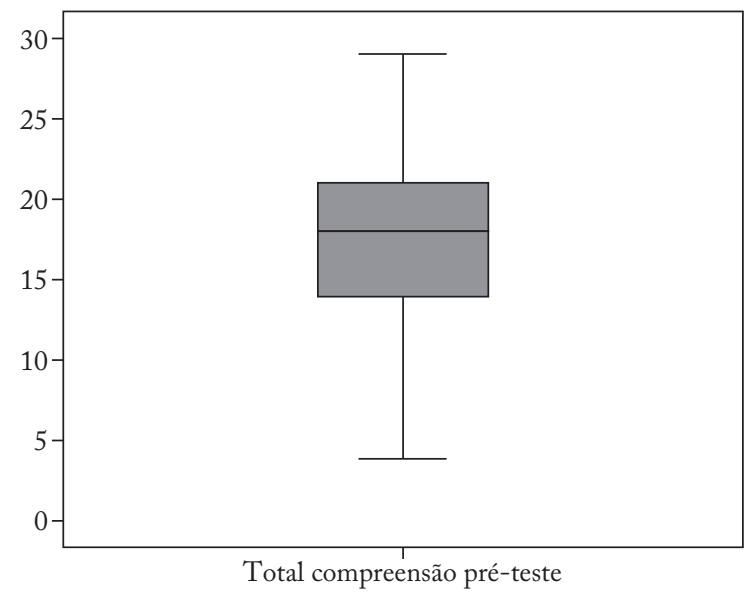

Fonte: Banco de dados da pesquisa.

Elaboração das autoras. 
optou-se por recorrer a análises de estatística paramétrica na testagem de efeitos de mudança entre os dois momentos de avaliação.

Recorreu-se a um teste $t$ para amostras emparelhadas para testar a existência de diferenças estatisticamente significativas na compreensão da leitura entre o pré e o pós-teste. Os resultados do teste $t$ forneceram evidência da existência de diferenças estatisticamente significativas no nível da compreensão entre o pré e o pós-teste, $t(1.141)=-31.08, \mathrm{p}<.001$. A magnitude do efeito foi moderada, $r=0,68$.

Para verificar em que medida as diferenças entre os resultados em compreensão se mantinham entre o pré e o pós-teste, controlando o efeito do nível de reconhecimento de palavras dos participantes, efectuou-se uma análise de covariância para medidas repetidas. Dado que o factor de medidas repetidas possui apenas dois níveis (pré e pós-teste), não foi calculado qualquer teste de esfericidade. Não se observou um efeito de interaç̧ão estatisticamente significativo entre os resultados de compreensão em leitura e os níveis de reconhecimento de palavras, $\mathrm{F}(1,1.140)=0.70, \mathrm{p}=0,40$. As diferenças entre o pré e o pós-teste no nível da compreensão mantêm-se, mesmo quando controlado o efeito do reconhecimento de palavras, $\mathrm{F}(1,1.140)=130.04, \mathrm{p}<0.001$.

\section{APRECIAÇÃO DA ESTABILIDADE DOS RESULTADOS}

A correlação entre os resultados em compreensão no pré e no pós-teste foi estatisticamente significativa, $\mathrm{r}=0,68, \mathrm{p}<0,001$, evidenciando uma dependência dos valores do pós-teste relativamente ao pré-teste. Por conseguinte, $46 \%$ da variância dos resultados em compreensão no pós-teste dependem dos resultados obtidos no pré-teste.

O coeficiente de correlação intraclasse foi de 0,68 , indicando que há alguma instabilidade nas posições relativas dos participantes no seio do grupo. No Quadro 5 apresenta-se o número de alunos que se mantiveram ou que alteraram a sua localização em termos de classe percentílica do primeiro para o segundo momento de avaliação.

$\mathrm{Na}$ generalidade, observaram-se ganhos na compreensão em leitura em todos os níveis de desempenho. A maioria dos alunos que no pré-teste se situaram na classe percentílica mais baixa (Classe 1) demonstrou melhorias de desempenho no pós-teste, com $35,4 \%$ a situar-se na classe percentílica imediatamente superior (Classe 2) e 25,5\% a situar-se na Classe 3 . Também os alunos que no pré-teste se situaram na Classe 2, obtiveram melhorias de resultados, com 48,8\% a situar-se na classe percentílica 3 e 12,9\% a situar-se na Classe 4 no pós-teste. De igual forma, observaram-se ganhos no grupo de alunos com desempenho médio no pré-teste (Classe 3), com 33\% a situar-se na Classe 4 e 14,5\% na Classe 5 no pós-teste. Também nos níveis superiores de desempenho no pré-teste se observaram ganhos, sendo que $50 \%$ dos alunos de Classe 4 obtiveram resultados de Classe 5 no pós-teste.

Esses resultados demonstram que o programa de intervenção pode exercer um efeito na melhoria dos níveis de compreensão não só de alunos com elevados níveis de desempenho, mas também em alunos com desempenhos inferiores. 


\section{COMPARAÇÃO DOS RESULTADOS DA AMOSTRA NA}

\section{PROVA DE AFERIÇÃO COM OS DADOS NACIONAIS}

$\mathrm{Na}$ análise de resultados na prova de aferição de língua portuguesa, consideraram-se apenas os resultados de 1.129 participantes, dado que 19 deles não realizaram a prova e não foi possível obter dados para outros dois participantes. No Gráfico 3 apresentam-se os resultados dos participantes no

Quadro 5 - Mudanças do pré para o pós-teste nas classes percentílicas de compreensão

\begin{tabular}{|c|c|c|c|c|c|c|c|}
\hline & \multicolumn{5}{|c|}{ Classe percentílica no pós-teste } & \multirow{2}{*}{ Total } \\
\hline & & 1 & 2 & 3 & 4 & 5 & \\
\hline \multirow{5}{*}{$\begin{array}{l}\text { Classe } \\
\text { percentílica } \\
\text { no pré-teste }\end{array}$} & 1 & $\begin{array}{c}162 \\
(34,1 \%)\end{array}$ & $\begin{array}{c}168 \\
(35,4 \%)\end{array}$ & $\begin{array}{c}121 \\
(25,5 \%)\end{array}$ & $\begin{array}{c}22 \\
(4,6 \%)\end{array}$ & $\begin{array}{c}2 \\
(0,4 \%)\end{array}$ & 475 \\
\hline & 2 & $\begin{array}{c}27 \\
(8,5 \%)\end{array}$ & $\begin{array}{c}86 \\
(27 \%)\end{array}$ & $\begin{array}{c}155 \\
(48,8 \%)\end{array}$ & $41(12,9 \%)$ & $\begin{array}{c}9 \\
(2,8 \%)\end{array}$ & 318 \\
\hline & 3 & $\begin{array}{c}5 \\
(1,8 \%) \\
\end{array}$ & $\begin{array}{c}22 \\
(8 \%) \\
\end{array}$ & $\begin{array}{c}117 \\
(42,4 \%) \\
\end{array}$ & $92(33,3 \%)$ & $40(14,5 \%)$ & 276 \\
\hline & 4 & 0 & 0 & $13(21,7 \%)$ & $17(28,3 \%)$ & $\begin{array}{c}30 \\
(50 \%)\end{array}$ & 60 \\
\hline & 5 & 0 & 0 & 0 & $\begin{array}{c}3 \\
(23,1 \%) \\
\end{array}$ & $10(76,9 \%)$ & 13 \\
\hline \multicolumn{2}{|l|}{ Total } & 194 & 276 & 406 & 175 & 91 & 1.142 \\
\hline
\end{tabular}

Fonte: Banco de dados da pesquisa.

Elaboração das autoras.

Gráfico 3 - Comparação dos resultados na prova de aferição de língua portuguesa de 2012 dos participantes com os dados nacionais

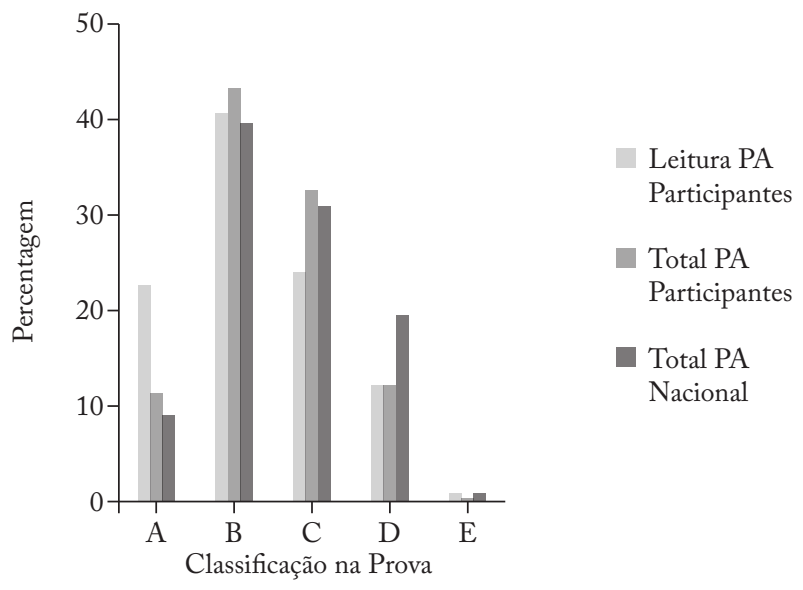

Fonte: Banco de dados da pesquisa.

Elaboração das autoras. 
total da prova de aferição e na parte 1 da prova (leitura), bem como os resultados obtidos em nível nacional pelos alunos portugueses no total da prova.

A percentagem de alunos que obteve classificações de nível A, B e C no total da prova é superior no grupo de participantes comparativamente com os resultados obtidos em nível nacional. Contrariamente, a percentagem de alunos com classificações totais de nível inferior - D e E - é superior nos dados nacionais. Verificou-se também a existência de uma percentagem mais elevada de classificações de nível A em resultados em leitura (parte 1 da prova), comparativamente com os resultados obtidos no total da prova, quer pelos participantes deste estudo, quer pelo universo de alunos em nível nacional. A maioria dos participantes deste estudo obteve classificações A ou B em leitura (63,2\%).

\section{DISCUSSÃO DOS RESULTADOS}

Este estudo procurou avaliar as mudanças no desempenho em compreensão da leitura em alunos do $4^{\circ}$ ano de escolaridade que realizaram o programa Aprender a compreender torna mais fácil o saber (Viana et al., 2010a). A comparação dos resultados obtidos no pré e no pós-teste mostrou a ocorrência de mudanças estatisticamente significativas com resultados médios superiores no final do programa. Além dessa comparação, procurou-se verificar em que medida os ganhos obtidos estavam condicionados pelos resultados antes do início do programa, bem como verificar se os maiores ganhos eram observados nos alunos com melhores resultados. Esses ganhos diferenciais para os alunos com melhores resultados têm sido discutidos na literatura como efeito de Mateus (Lopes, 2001). Os resultados obtidos indicam que, embora os ganhos se apresentem associados ao desempenho inicial, em todos os níveis de desempenho se observam ganhos do pré para o pós-teste. Os resultados da análise de covariância indicam que os ganhos observados não são condicionados pelo nível de reconhecimento de palavras.

A comparação com os resultados dos exames nacionais de língua portuguesa indica que os alunos que participaram no projeto tiveram resultados superiores, expressos na percentagem de alunos que obtiverem níveis superiores de desempenho. A análise desses resultados deve ser ponderada em virtude do design usado. A inexistência de um grupo de controlo limita a possibilidade de associar as mudanças observadas à implementação do programa. A aplicação do programa incluindo um grupo de controlo e o follow-up dos alunos nos anos seguintes à realização do programa bem como uma análise da avaliação pelos professores que implementam o programa são aspetos a contemplar em investigações posteriores.

\section{REFERÊNCIAS}

Barrett, T. Taxonomy of reading comprehension. In: Smith, R.; Barrett, T. (Eds.). Teaching reading in the middle class. Boston, MA: Addison-Wesley, 1976. p. 51-58. 
Brown, A. Metacognitive development and reading.In: Spiro, R.; Bruce, B.; Brewer, W. (Eds.). Theoretical issues in reading comprehension. Perspectives from cognitive psychology, linguistics, artificial intelligence, and education. Hillsdale: Lawrence Erlbaum Associates, 1980. p. 453-481.

Byrne, B. Structural equation modeling with Mplus: basic concepts, applications and programming. New York: Routledge Academic, 2011.

Cadime, I.; Ribeiro, I.; Viana, F. L. TCL - Teste de compreensão da leitura. Lisboa: Edições CEGOC-TEA, 2012.

Català, G.; Català, M.; Molina, E.; Monclús, R. Evaluación de la comprensión lectora: pruebas ACL ( $1^{\circ}-6^{\circ}$ de primaria). Barcelona: Editorial Graó, 2001.

Curto, L.; Morillo, M.; Teixidó, M. Escrever e ler. Porto Alegre: Artmed, 2000. v. 1. Field, A. Discovering statistics using SPSS. Los Angeles: Sage, 2009.

Flavell, J. Cognitive monitoring. In: Dickson, W.P.(Ed.). Children's oral communication skills. New York: Academic Press, 1981.

Géninet, A.; Michèle, G.; Garanderie, T. P.; Gaté, J.-P. Vocabulaire de la gestion mentale. Lion: Chronique Sociale, 2009.

Giasson, J. A compreensão na leitura. 2. ed. Porto: Edições Asa, 2000.

. La lecture: de la théorie à la pratique. Bruxelles: De Boeck \& Larcier, 2005.

Hu, L.; Bentler, P. M. Cutoff criteria for fit indexes in covariance structure analysis: conventional criteria versus new alternatives. Structural Equation Modeling: A Multidisciplinary Journal, United Kingdom: Taylor \& Francis, v. 6, n. 1, p. 1-55, 1999. IRwIn,J. Teaching reading comprehension processes. Englewood Cliffs, NJ: Prentice-Hall, 1986. Lencastre, L. Leitura: a compreensão de textos. Lisboa: Fundação Calouste Gulbenkian, 2003.

Lopes, J. Problemas de comportamento, problemas de aprendizagem e problemas de "ensinagem". Coimbra: Quarteto Editores, 2001.

McGuinness, D. Language development and learning to read: the scientific study of how language development affects reading skill. Cambridge: MIT Press, 2005.

. O ensino da leitura. O que a ciência nos diz sobre como ensinar a ler. Porto Alegre: Artes Médicas, 2006.

Mendonça, S. Provas de avaliação da compreensão leitora: estudo de validação. 44f. Dissertação (Mestrado em Psicologia) - Escola de Psicologia da Universidade do Minho, Braga, 2008.

Mills. K. K.; Just, M. A. The influence of connectives on sentence comprehension. Journal of Memory and Language, United Kingdom: Elsevier, v. 33, n. 1, p. 128-147, 1994. Ministério da Educação. Resultados do estudo internacional PISA 2000. Lisboa: Direç̧ão-Geral de Inovação e Desenvolvimento Curricular, Ministério da Educação, 2001. Disponível em: <https://www.oecd.org/portugal/33685403.pdf>. Acesso em: 20 set. 2012. 
Ministério da Educação. PISA 2006 - competências científicas dos alunos portugueses. Lisboa: Direcção-Geral de Inovação e Desenvolvimento Curricular, Ministério da Educação, 2007. Disponível em: <http://www.netprof.pt/forum/ PDF/pisa06.pdf>. Acesso em: 20 set. 2012.

PISA 2009 - competências dos alunos portugueses. Síntese de resultados. Lisboa: Direcção-Geral de Inovação e Desenvolvimento Curricular, Ministério da Educação, 2010. Disponível em: <https://www.oecd.org/portuga1/33685403.pdf〉. Acesso em: 20 set. 2012.

Mosenthal, J. The comprehension experience. In: Muth, D. (Ed.). Children's comprehension of text. Newark, DA: International Reading Association, 1989.

Pennac, D. Como um romance. 7. ed. Porto: Edições ASA, 1996.

Rumelhart, D. Schemata: the building blocks of cognition. In: Spiro, R.; Bruce, B.; Brewer, W. (Eds.). Theoretical issues in reading comprehension. Perspectives from cognitive psychology, linguistics, artificial intelligence, and education. Hillsdale: Lawrence Erlbaum Association, 1980.

Sánchez Miguel, E. Comprensión y redacción de textos: dificultades y ayudas. 3. ed. Barcelona: Edebé, 2002.

(Coord.). La lectura en el aula. Qué se hace, qué se debe hacer y qué se puede hacer. Barcelona: Graó, 2010.

Shaughnessy, M.; Veenman, M.; Kleyn-Kennedy, C. Meta-cognition. A recent review of research, theory and perspectives. New York: Nova Science Publishers, 2008.

Sim-Sim, I.; Viana, F. Para a avaliação do desempenho de leitura. Lisboa: Ministério da Educação, Gabinete de Estatística e Planeamento da Educação, 2007.

Sim-Sim,I.; Duarte, C.; Micaelo, M. O ensino da leitura: a compreensão de textos. Lisboa: Ministério da Educação, Direcção-Geral de Inovação e Desenvolvimento Curricular, 2007.

SolÉ, I. Estrategias de lectura. Barcelona: Graó Editorial; ICE; Universidade de Barcelona, 1992.

Viana, F. L.; Ribeiro, I. PRP - Prova de reconhecimento de palavras. Lisboa: Edições CEGOC-TEA, 2010.

VIANA, F. L. et al. Aprender a compreender torna mais fácil o saber. Coimbra: Almedina, 2010a.

VIAna, F. L. et al. O ensino da compreensão leitora: da teoria à prática pedagógica. Um programa de intervenção para o $1^{\circ}$ ciclo do ensino básico. Coimbra: Almedina, 2010b. Disponível em: <http://hdl.handle.net/1822/11219>. Acesso em: 29 out. 2017.

Vygotsкy, L. Pensamento e linguagem. Lisboa: Relógio d’Água, 2007. 
Anexo 1

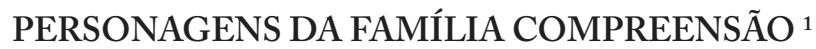
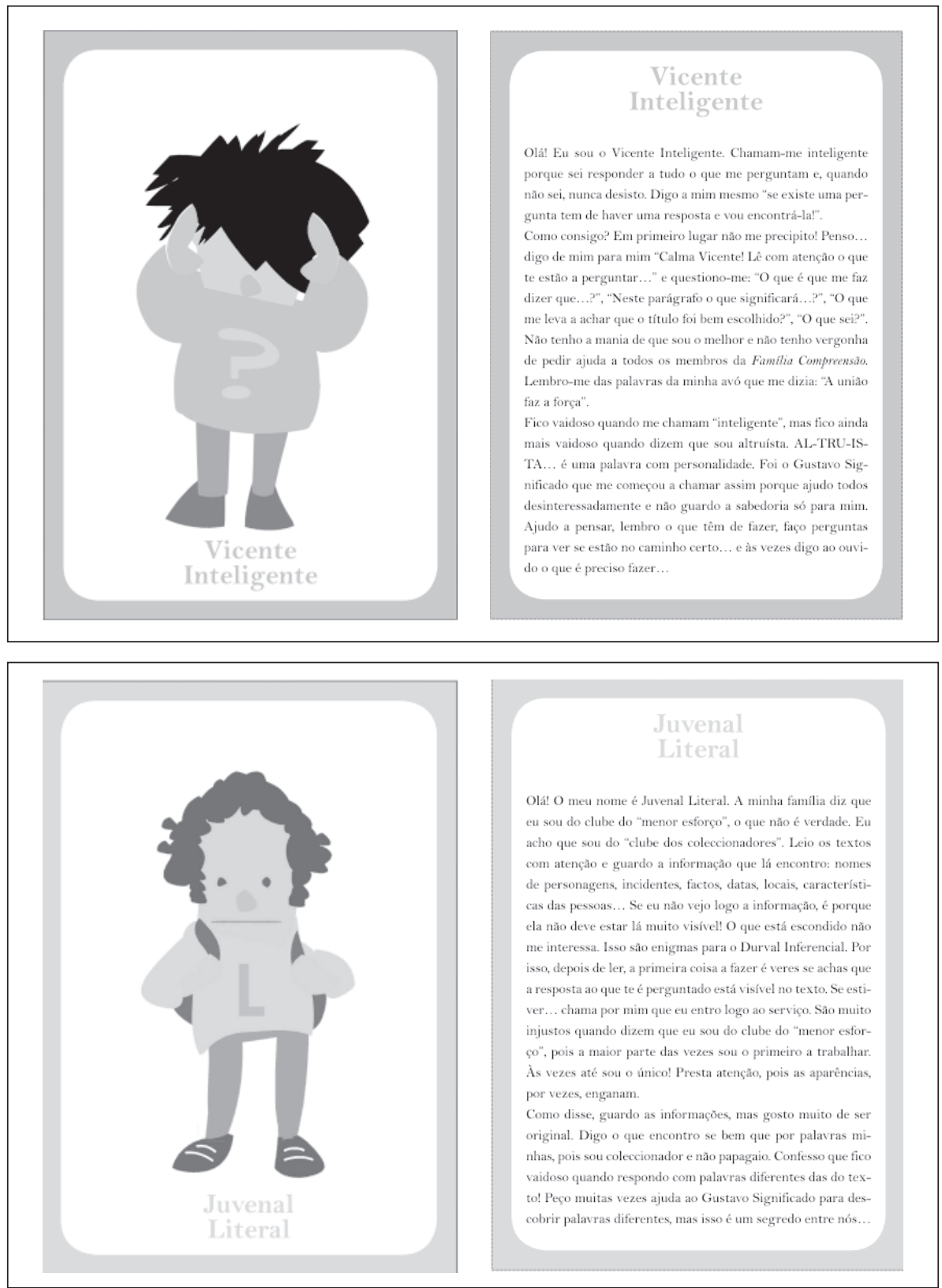

Continua...

1 O livro de apoio para os professores e a base de dados estão disponíveis em: $<$ http://hdl. handle.net/1822/34996>. Acesso em: 7 nov. 2017. 


\section{Anexo 1 - Continuação}
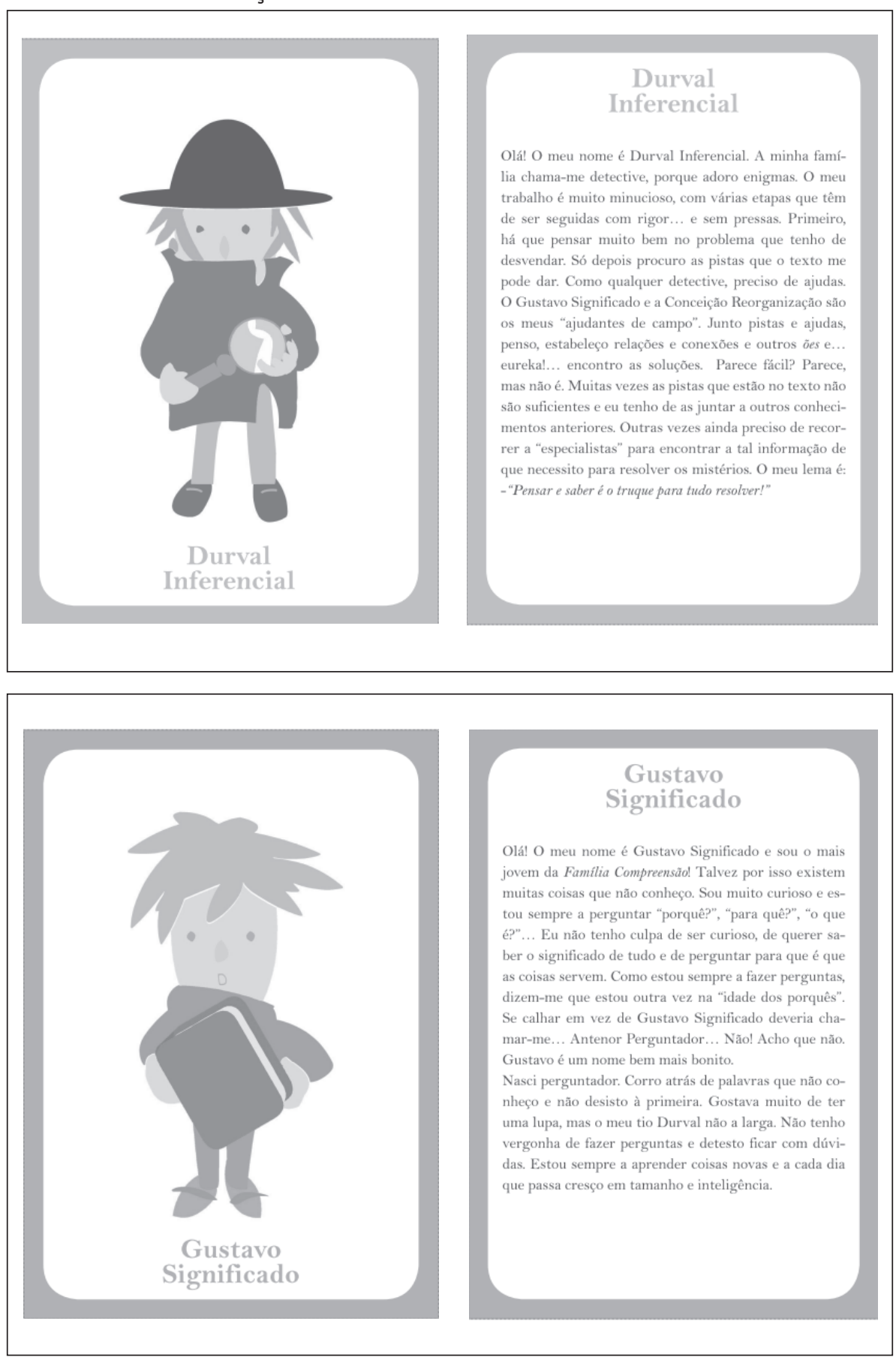

Continua... 


\section{Anexo 1 - Continuação}
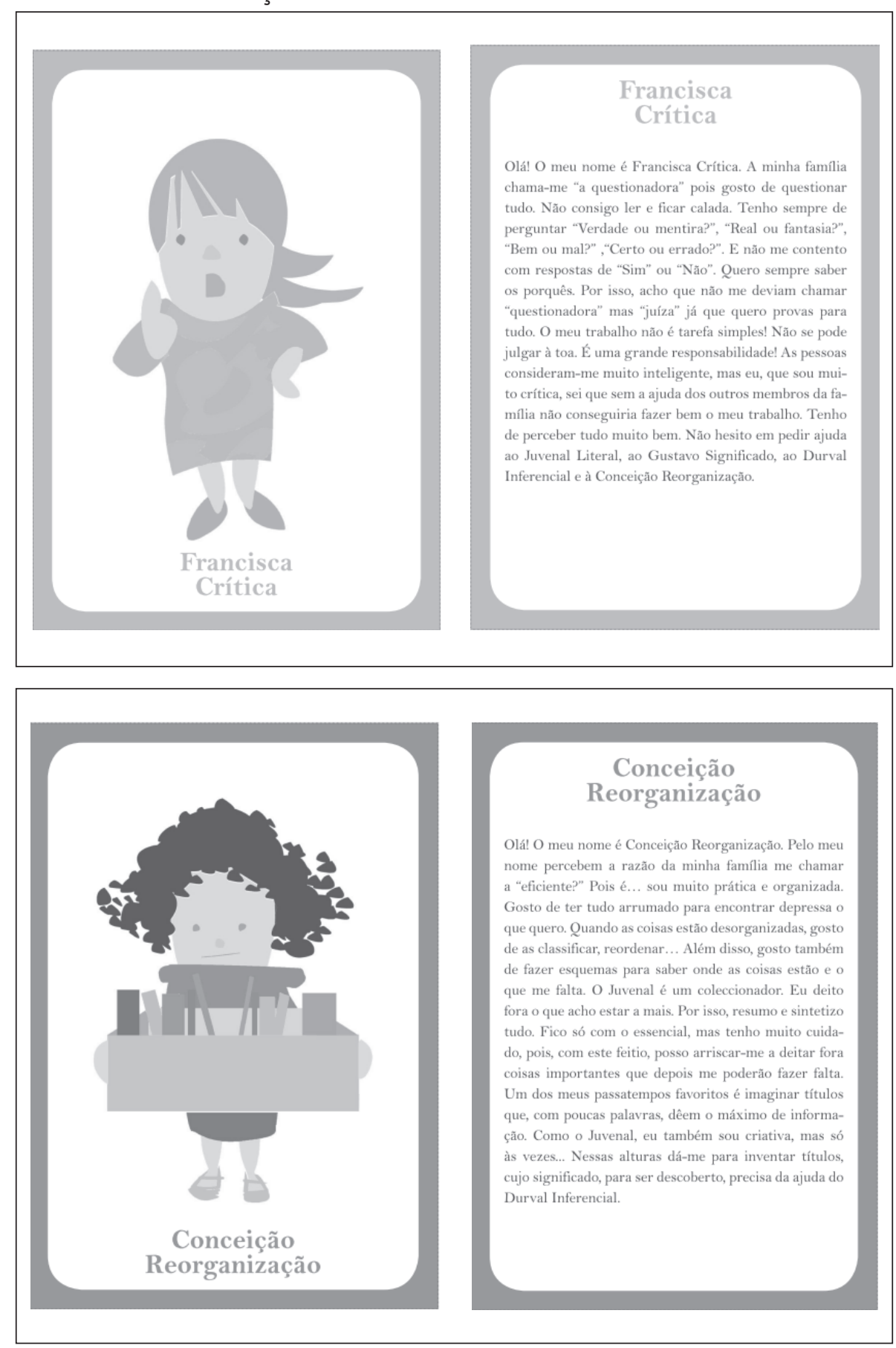

Continua... 


\section{SOBRE AS AUTORAS}

Fernanda Leopoldina Viana é doutorada em psicologia pela Universidade do Minho (Portugal). Professora da mesma instituição.

E-mail: fviana@ie.uminho.pt

Irene Cadime é doutorada em psicologia pela Universidade do Minho (Portugal).

E-mail: irenecadime@ie.uminho.pt

Sandra Santos é doutoranda em psicologia pela Universidade do Minho (Portugal).

E-mail:b5285@psi.uminho.pt

Sara Brandẽo é doutoranda em psicologia pela Universidade do Minho (Portugal).

E-mail:sarabran@gmail.com

Iolanda Ribeiro é doutorada em psicologia pela Universidade do Minho (Portugal). Professora da mesma instituição.

E-mail:iolanda@psi.uminho.pt

Recebido em 24 de abril de 2015

Aprovado em 18 de agosto de 2015 